\title{
Allocation \& Utilization of Sports Amenities
}

\author{
Manzoor Khan ${ }^{1}$, Alamgir Khan ${ }^{2 *}$ and Salahuddin Khan ${ }^{2}$ \\ ${ }^{1}$ Faculty of Education, Hazara University Manshera, Pakistan \\ ${ }^{2}$ Department of Sports Science \& Physical Education, Gomal University, Pakistan
}

*Corresponding author: Alamgir Khan, Department of Sports Science \& Physical Education Gomal University, Pakistan

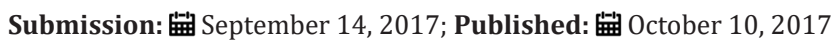

\begin{abstract}
The present research study aimed to assess the perception of heads of collages (HOCs), physical education teachers (PETs) and students regarding the available resources of sports and its utilization. The target population of this particular research study was comprised of all male and female heads of collages (HOCs), physical education teachers (PETs) and all the students of sports sciences \& physical education of Government Degree Collages of Dist Bannu Kp Pakistan. Similarly two male and two females $(02+02=04)$ heads of collages (HOCs), two females and five male (02+05=08) physical education teachers (PETs) and fifty females and fifty males $(50+50=100)$ students of sports sciences \& physical education were taken as sample of the study by using convenient sample technique. For the collection of data, the researcher developed three separate questionnaires ( 01 for heads, 01 for physical education teachers and 01 for students of physical education). The collected data were tabulated and analyzed by using percentage as a statistical tool.
\end{abstract}

After data analysis, the researcher draws the following conclusions

a) The data perceived from HODs of collages shown that all kind of sports facilities are given to the collages from their governing bodies.

b) The date perceived from physical education teachers shown that sufficient sports facilities are given and properly utilized for the improvement of sports.

c) The date perceived from the students of sports sciences and physical education shown that the available resources of sports in the shape of staff, equipment's, space and financial resources are insufficient and similarly the available sports facilities are not properly utilized.

Keywords: Allocation; Utilization; Sports amenities; Bannu; Kp; Pakistan

\section{Introduction}

Research evidence shows that number of high quality sports facilities is given to players in developed countries. Result of availability of standard facilities directly shown from the fact that level of sports participation in developed countries is high as compared to developing countries of the world [1]. For the smooth organization of sports programs, it is needed to make available all the required facilities for athlete in playing area (Casa et al, 2012). Lacking of availability of required resources adversely affect the performance of athlete. In sports many of athletes' loss their performance due to non-availability of resources [2]. According to Gillespie et al. [3] Life and sports go together. It means that both life and sports are interrelated with each other. Sport promotes health and lengthens live, Modify character, reign behavior and develop efficiency of the body. Through sports participation one become capable of bearing mental and physical pressures and move active and efficient in doing his/her job. According to Kelley [4] Sports participation is the only positive and effective means for getting relief from different psychological problems. A person with good physical and mental health can easily prove his/her worth in family and in a society.
According Ancona et al. [5] Sports activities, needs some resources for it smooth organization? The author further says that resource is an aid or support that is needed to assist, to sketch and to achieve something. Sports need many resources such as staff, space, and equipment for its application and propagation. Clearly, one of the most important skill for a sports administrator is to determine the needs and to identify resources that can resolve these needs and then to acquire the needed resources (Chelladurai, 2006). Few years back the sports programs were limited to a few events, the squads were small and the players were not equipped so elaborately and completely as they are today [6].

\section{Objectives of the Study}

To investigate the perception of students regarding the availability and utilization of sports amenities.

\section{Methods and Material}

The target population of this particular research study was comprised of all male and female heads of collages (HOCs), physical education teachers (PETs) and all the students of sports sciences \& physical education of Government Degree Collages of Dist Bannu 
Kp Pakistan. Similarly two male and two females $(02+02=04)$ heads of collages (HOCs), two females and five male $(02+05=08)$ physical education teachers (PETs) and fifty females and fifty males $(50+50=100)$ students of sports sciences \& physical education) were taken as sample of the study by using convenient sample technique. For the collection of data, the researcher developed three separate questionnaires $(01$ for heads, 01 for physical education teachers and 01 for students of physical education). The collected data were tabulated and analyzed by using percentage as a statistical tool.

\section{Presentation and Analysis of Data}

(Table 1-3)

Table 1: Shows the provision of sports facilities perceived by heads of collages (HOCs).

\begin{tabular}{|c|c|c|c|c|c|c|}
\hline S. No & Statement & Yes & $\%$ & No & $\%$ & Total \\
\hline 1 & Fund for sports is given to collage & 4 & 100 & 0 & 0 & 4 \\
\hline 2 & Available sports fund is sufficient & 3 & 75 & 1 & 25 & 4 \\
\hline 3 & Available sports funds need to be increase & 3 & 75 & 1 & 25 & 4 \\
\hline 4 & $\begin{array}{l}\text { You as head (HOC) give the available funds of } \\
\text { sports to the concerned teachers }\end{array}$ & 4 & 100 & 0 & 0 & 4 \\
\hline 5 & $\begin{array}{l}\text { You as head (HOC) believed that available sports } \\
\text { funds utilize properly by the concerned teachers }\end{array}$ & 4 & 100 & 0 & 0 & 4 \\
\hline
\end{tabular}

Table 2: Showing the provision of sports facilities and its utilization as perceived by physical education teachers.

\begin{tabular}{|c|c|c|c|c|c|c|}
\hline S. No & Statement & Yes & $\%$ & No & $\%$ & Total \\
\hline 1 & Sports facilities are given to you & 8 & 100 & 0 & 0 & 8 \\
\hline 2 & Available Sports facilities are satisfactory & 6 & 75 & 2 & 25 & 8 \\
\hline 3 & Sports facilities need to be increased & 6 & 75 & 2 & 25 & 8 \\
\hline 4 & $\begin{array}{c}\text { You as a physical education teacher (PET) properly } \\
\text { utilize the available sports facilities }\end{array}$ & 8 & 100 & 0 & 0 & 8 \\
\hline 5 & $\begin{array}{l}\text { You as a physical education teacher (PET) provide } \\
\text { the required sports facilities to the students }\end{array}$ & 8 & 100 & 0 & 0 & 8 \\
\hline 6 & $\begin{array}{l}\text { You as a physical education teacher (PET) properly } \\
\text { maintain the available sports facilities }\end{array}$ & 8 & 100 & 0 & 0 & 8 \\
\hline 7 & $\begin{array}{l}\text { Proper check \& balance is kept by head of institute } \\
\text { on the available sports facilities }\end{array}$ & 5 & 62 & 2 & 28 & 8 \\
\hline
\end{tabular}

Table 3: Showing the provision of sports facilities and its utilization as perceived by physical education students.

\begin{tabular}{|c|c|c|c|c|c|c|}
\hline S. No & Statement & Yes & $\%$ & No & $\%$ & Total \\
\hline 1 & Sports facilities are provided to you & 80 & 80 & 20 & 20 & 100 \\
\hline 2 & Available Sports facilities are satisfactory & 95 & 95 & 5 & 5 & 100 \\
\hline 3 & Sports facilities need to be increased & 100 & 100 & 0 & 0 & 100 \\
\hline 4 & $\begin{array}{l}\text { Proper check \& balance is kept by head and } \\
\text { physical education teachers of institute on the } \\
\text { available sports facilities }\end{array}$ & 0 & 0 & 100 & 100 & 100 \\
\hline 5 & $\begin{array}{l}\text { Sports facilities properly utilize for the arranging } \\
\text { sports activities }\end{array}$ & 0 & 0 & 100 & 100 & 100 \\
\hline
\end{tabular}

\section{Result and Discussion}

On the basis of analysis it is find out by the researcher that all heads of collages opined that all sports facilities in the shape of qualified staff, proper space and sufficient equipment are provided to the collages. The findings of this research study is supported by Crawford [7] by indicating that smooth functioning of sports programs need the provision of all the required facilities in the shape of qualified staff, proper space and sufficient playing equipment's. The findings of the study conducted by Fasoli \& Johns [8] also inline of the present study because the concluded that sports programs need the availability of all the necessary equipment's. The author further stated that lacking of facilities of sports could create problems in the promotion of sports activities.
It is indicated by the present study that majority of physical education teachers opined that all sports facilities are provided and properly utilize for the development and improvement of sports. This finding of the study is also inline of the findings draw by Kim [9] that availability and utilization of facilities is the key component for sports development. The findings of the study conducted by conducted by Matheson \& Baade [10] shown that non-availability and improper use of sports facilities create hindrance in the way of sports.

\section{Conclusion}

Based on findings the researcher arrived at the following conclusions 
1. The data perceived from HODs of collages shown that all kind of sports facilities are given to the collages from their governing bodies

2. The date perceived from physical education teachers shown that sufficient sports facilities are given and properly utilized for the improvement of sports

3. The date perceived from the students of sports sciences and physical education shown that the available resources of sports in the shape of staff, equipment's, space and financial resources are insufficient and similarly the available sports facilities are not properly utilized.

\section{Recommendations of the Study}

On the basis of conclusion the researcher recommended that

1. All the required sports facilities may be provided to the students in their concerned institutions.

2. Qualified sports staff may be provided to the students in their concerned institutions.

3. The available facilities may be properly utilized for the promotion of sport in at collages level.

\section{References}

1. Rafoss K, Troelsen J (2010) Sports facilities for all? The financing, distribution and use of sports facilities in Scandinavian countries. Sport in society 13(4): 643-656.

2. Samagaio A, Couto E, Caiado J (2009) Sporting, financial and stock market performance in English football: an empirical analysis of structural relationships. Centre for Applied Mathematics and Economics (CEMAPRE) working papers.

3. Gillespie DL, Leffler A, Lerner E (2002) If it weren't for my hobby, I'd have a life: dog sports, serious leisure, and boundary negotiations. Leisure Studies 21(3-4): 285-304.

4. Kelley TM (2004) Positive psychology and adolescent mental health: False promise or true breakthrough? Adolescence 39(154): 257-278.

5. Ancona DG, Caldwell DF (1992) Bridging the boundary: External activity and performance in organizational teams. Administrative science quarterly 37(4): 634-665.

6. Cook PJ, Frank RH (2010) The winner-take-all society: Why the few at the top get so much more than the rest of us. Random House.

7. Crawford WH (1963) A Guide for Planning Indoor Facilities for College Physical Education.

8. Fasoli L, Johns V (2007) Children's services in remote Australian Indigenous communities: practices and challenges. Canadian Journal of Native Education 30(1): 83-101.

9. Kim D, Kim SY (1995) QUESC: An instrument for assessing the service quality of sport centers in Korea. Journal of sport management 9(2): 208-220.

10. Matheson VA, Baade RA (2004) Mega-sporting events in developing nations: playing the way to prosperity? South African journal of economics 72(5): 1085-1096. 